\title{
Ewing's Tumors over the Age of 40 - a Retrospective Analysis of 47 Patients Treated According to the Inter- national Clinical Trials EICESS 92 and EURO-E.W.I.N.G. 99
}

\author{
Sebastian Pieper ${ }^{\mathrm{a}} \quad$ Andreas Ranft $^{\mathrm{a}, \mathrm{b}} \quad$ Gabriele Braun-Munzinger $^{\mathrm{a}} \quad$ Heribert Jürgens $^{\mathrm{a}}$ \\ Michael Paulussen ${ }^{c}$ Uta Dirksen ${ }^{a}$ \\ a Dept. of Pediatric Hematology and Oncology, University Children's Hospital,

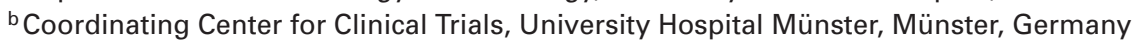 \\ ${ }^{c}$ Dept. of Pediatric Oncology and Hematology, University Children's Hospital (UKBB), Basel, Switzerland
}

Key Words

Adults - Chemotherapy · Ewing's tumor - Radiotherapy . Surgery

\section{Summary}

Background: Ewing's tumors (ET) are rare in patients over the age of 40 years. Published data on presentation, treatment, and clinical outcome are limited. Patients and Methods: We present a retrospective analysis of data from 47 patients in this age group diagnosed with ET and enrolled in the 2 consecutive trials, EICESS 92 and EURO-E.W.I.N.G. 99. The median age at diagnosis was 47.7 years (range, 40-68.6 years). Results: The median follow-up was 2.23 years from diagnosis (range, $0.35-12.92$ years). $72.3 \%$ of patients were found to have localized disease, and $27.7 \%$ had primary metastases. Good clinical response to induction therapy was observed in $55 \%$, and $73 \%$ of patients showed good histological response. The event-free survival was 0.77 at 1 year and 0.50 at 3 years $(n=44)$. Conclusion: ET are rare in patients over the age of 40 years. With adequate multimodal therapy, the results in terms of survival are comparable to those in adolescence. Specific age-adapted treatment regimens are not established. Patients should be enrolled in international trials, and if necessary treatment should be adjusted for lower tolerance and co-morbidity.

\author{
Schlüsselwörter \\ Erwachsene - Chemotherapie - Ewing-Tumor . \\ Radiotherapie · Chirurgie
}

\section{Zusammenfassung}

Hintergrund: Ewing-Tumoren (ET) treten selten bei Patienten im Alter von über 40 Jahren auf. Entsprechend limitiert sind die Daten zu Klinik, Therapie und Überleben bei diesen Patienten. Patienten und Methoden: Der retrospektiven Analyse lagen Daten von 47 Patienten zugrunde, bei denen im Alter von über 40 Jahren die Diagnose eines ET gestellt wurde. Medianes Alter bei Diagnosestellung war 47,7 Jahre (Range, 40-68,6 Jahre). Die Behandlung erfolgte nach den Studien EICESS 92 oder EURO-E.W.I.N.G. 99. Ergebnisse: Der Nachbeobachtungszeitraum betrug 2,23 Jahre (Range, 0,35-12,92 Jahre) nach Diagnosestellung. Bei $72,3 \%$ der Patienten wurde eine lokalisierte Erkrankung diagnostiziert, 27,7\% hatten primäre Metastasen. Gutes klinisches Ansprechen auf die Induktionstherapie zeigten $55 \%(n=20)$ und $73 \%$ der Patienten zeigten gutes histologisches Ansprechen. Das ereignisfreie Überleben (EFS) lag bei 0,77 nach einem und 0,50 nach 3 Jahren ( $n=44)$. Schlussfolgerungen: Bei adäquater multimodaler Therapie sind die Ergebnisse für Patienten über 40 Jahre in Bezug auf das Überleben vergleichbar mit denen junger Patienten. Spezifische altersangepasste Behandlungsprotokolle sind nicht etabliert. Patienten sollten daher in die aktiven internationalen Studien eingebracht werden, um, sofern notwendig, die Behandlung an eine geringere Toleranz und Komorbiditäten anzupassen.

\begin{tabular}{ll}
\hline KARGER & ( ) 2008 S. Karger GmbH, Freiburg \\
$\begin{array}{l}\text { Fax +497614520714 } \\
\text { Information@Karger.de } \\
\text { www.karger.com }\end{array}$ & $\begin{array}{l}\text { Accessible online at: } \\
\text { www.karger.com/onk }\end{array}$
\end{tabular}




\section{Introduction}

Ewing's tumor (ET) is the second most common osseous tumor of childhood, adolescence, and young adulthood $[1,2]$. A new era of ET diagnosis and research was opened in the mid 1990s when the tumor-specific fusion gene EWS/Fli1 was described which allows precise allocation of bone and soft tissue sarcomas [3] to the ET family [4]. The introduction of a multimodal treatment concept consisting of combination chemotherapy and local therapy modalities, including surgery and radiation, achieved $60-70 \%$ overall survival in patients with localized disease [2, 5-14]. The majority of clinical trials accepted pediatric and adolescent patients, with a median reported age of $<15$ years [8,15-17]. Information on ET in patients over the age of 40 years is scarce.

EICESS 92, a joint trial of the UK Children's Cancer and Leukaemia Group (CCLG) and the German Society of Pediatric Oncology and Hematology (Gesellschaft für Pädiatrische Onkologie und Hämatologie, GPOH) was the first trial open for patients up to age 35, and the international trial EUROE.W.I.N.G. 99 accepts patients up to age 50 years. Moreover, in both of these studies, the trial center in Münster, Germany, registered and followed up patients $>50$ years as non-study patients, and collected relevant data from this group. The present report gives a brief summary of the disease presentation, treatment, and outcome in such patients allocated to an appropriate protocol treatment on an intent-to-treat basis.

\section{Patients and Methods}

\section{Patient Characteristics}

A total of 47 patients over age 40 with newly diagnosed ET, enrolled between August 1992 and February 2005, were identified among a cohort of 1,720 patients registered at the GPOH Ewing trial center in Münster, Germany. The median age at diagnosis was 47.7 years (range, $40-68.6$ years); $20(42.6 \%)$ patients were females, $27(57.4 \%)$, males. The median followup was 2.23 years from diagnosis (range, $0.35-12.92$ years) (table 1 ).

\section{Treatment}

Sixteen patients were treated according to EICESS 92, and 31 patients according to EURO-E.W.I.N.G. 99. Patients gave written informed consent according to institutional and national guidelines. The trials had been approved by the appropriate ethics committees. Sixteen patients qualified as regular study patients of EURO-E.W.I.N.G. 99; all other patients were registered as follow-up patients (table 1). The major reasons for exclusion from regular study patient status were registration or start of treatment $>45$ days after biopsy, more than 1 course of other chemotherapy, and age $>50$ years (EICESS 92: age > 35 years). Local treatment consisted of radiotherapy and surgery, and was individually planned for each patient. The EICESS 92 protocol accomplished 2 parallel risk-adapted randomized trials. Risk groups were defined by disease stage and tumor volume. Patients with localized tumors $<100 \mathrm{ml}$ were stratified into the standard risk group, those with tumors $>100 \mathrm{ml}$ and/or metastatic disease were allocated to the high risk group. All of the patients received a 4-drug induction treatment of ifosfamide, vincristine, doxorubicin, and actinomycin D (VAIA). For consolidation treatment, either VAIA or VACA (cyclophosphamide replacing ifosfamide) was randomly allocated to standard risk
Table 1. Patient characteristics

\begin{tabular}{|c|c|}
\hline \multicolumn{2}{|l|}{ EICESS, n (\%) } \\
\hline Study patients & $0(0)$ \\
\hline Follow-up patients & $16(100)$ \\
\hline Total & $16(100)$ \\
\hline \multicolumn{2}{|l|}{ EURO-E.W.I.N.G. 99, n (\%) } \\
\hline Study patients & $16(52)$ \\
\hline Follow-up patients & $15(48)$ \\
\hline Total & $31(100)$ \\
\hline \multicolumn{2}{|l|}{ Sex, n (\%) } \\
\hline Male & $27(57.4)$ \\
\hline Female & $20(42.6)$ \\
\hline Age at diagnosis, years, median (range) & $47.7(40-68.6)$ \\
\hline \multicolumn{2}{|l|}{ Primary tumor site, n (\%) } \\
\hline Head/neck & $5(10.6)$ \\
\hline Upper extremity & $3(6.4)$ \\
\hline Chest & $9(19.2)$ \\
\hline Spinal column & $4(8.5)$ \\
\hline Abdomen & $3(6.4)$ \\
\hline Pelvis & $12(25.5)$ \\
\hline Lower extremity & $11(23.4)$ \\
\hline \multicolumn{2}{|l|}{ Primary tumor type, n (\%) } \\
\hline Osseous & $32(68.1)$ \\
\hline Extra-osseous & $15(31.9)$ \\
\hline Primary tumor volume, ml, median (range) & $185(1-2,836)$ \\
\hline \multicolumn{2}{|l|}{ Extent of disease, $\mathrm{n}(\%)$} \\
\hline Localized & $34(72.3)$ \\
\hline Metastases & $13(27.7)$ \\
\hline Lung & 8 \\
\hline Bone & 5 \\
\hline Bone marrow & 1 \\
\hline Lymph nodes & 3 \\
\hline Other & 4 \\
\hline
\end{tabular}

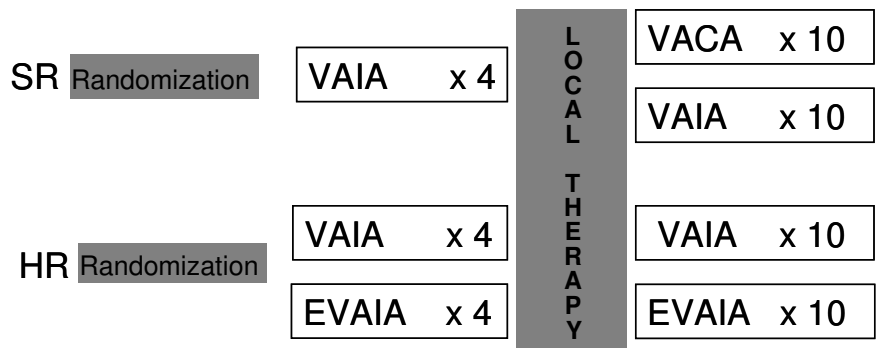

Fig. 1. EICESS 92 treatment strategy.

patients. In the high risk arm, VAIA treatment was randomized against EVAIA with the addition of etoposide (E) [18, 19] (fig. 1).

The EURO-E.W.I.N.G. 99 protocol employs vincristine, ifosfamide, doxorubicin, and etoposide (VIDE) induction chemotherapy, followed by risk-adapted randomized treatment [20]. Patients are stratified into risk groups according to prognostic factors including treatment-independent parameter such as presence and site of metastases, discriminating between pulmonary and extrapulmonary, metastases. In localized disease, the volume of the primary tumor, with a 200-ml cut-off, and/or histological response to induction chemotherapy are critical factors for stratification into the standard or high risk group. Standard risk patients (R 1) are randomized for consolidation treatment with either vincristine, actinomycin $\mathrm{D}$, and ifosfamide (VAI) or vincristine, actinomycin D, and cyclophosphamide (VAC). High risk patients ( $\mathrm{R} 2$ ) are randomized for high dose 


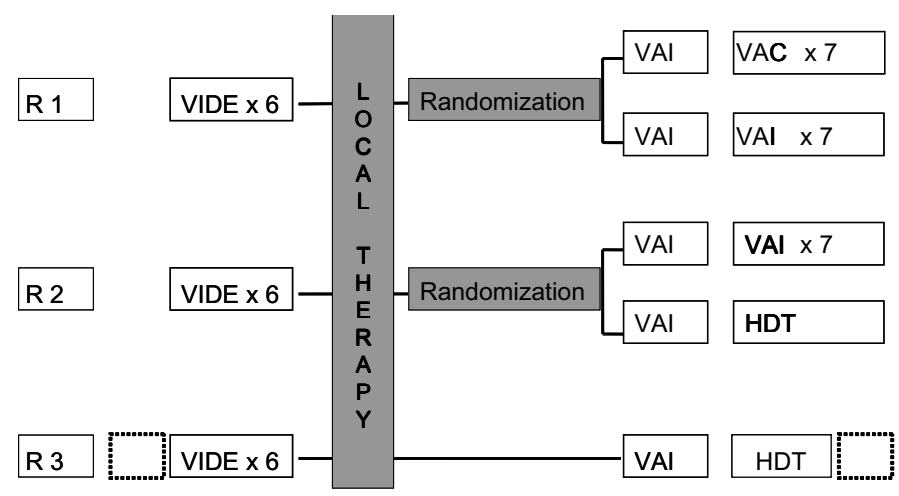

Fig. 2. EURO-E.W.I.N.G .99 treatment strategy.

busulfan/melphalan (Bu-Mel) versus VAI. Patients with extra-pulmonary metastatic disease (R 3) are not randomized, but high dose chemotherapy using Bu-Mel, treosulfan-Mel, or tandem Mel-E followed by autologous stem cell reinfusion or participation in a phase II study is recommended. The EURO-E.W.I.N.G. 99 trial is ongoing and still recruiting patients (fig. 2).

In the EICESS 92 trial, preoperative radiotherapy was frequently used [18]. The EURO-E.W.I.N.G. 99 protocol, however, based on a growing awareness of the prognostic impact of histological response, recommends preoperative radiotherapy only to avoid intralesional surgery, e.g. in the case of poor clinical response to chemotherapy [21-23]. Surgery was recommended for all patients, if feasible.

\section{Statistical Analysis}

Statistical analyses were performed using the SPSS Statistical Package 14.02 (SPSS Inc., Chicago, IL, USA) and SAS 9.1.3. (SAS Institute Inc, Cary, NC, USA). Distributions of survival curves/times (including eventfree survival (EFS) and overall survival (OS)) were estimated by the Kaplan-Meier method. Survival time starts at the day of diagnosis and ends at the date of first event (EFS) or death (OS) or the date of the patient's most recent consultation when all living patients (OS) and patients without event (EFS) were censored. An event was defined as relapse (local or metastatic), progression under therapy (assessable tumor growth), secondary malignancy, or death [24]. Group comparisons were calculated using the log-rank statistic [25-27]. Multivariate analyses were performed by Cox's proportional hazard method [28]. The significance level was set at $\mathrm{p}<0.05$ for two-sided test. No alpha corrections were done for multiple testing.

\section{Results}

\section{Baseline Characteristics of the Study Population}

Patient characteristics are given in table 1. The histopathological diagnosis was Ewing's sarcoma (including atypical Ewing's sarcoma) in 31 patients $(66 \%)$, and peripheral primitive neuroectodermal tumor (PNET) in 16 patients. Similar to the observations in younger patients, this difference in histology was of no prognostic value (data not shown). ET of the bone was diagnosed in 32 patients $(68.1 \%)$, extraosseous ET in $15(31.9 \%)$. The prevalent primary tumor site was the pelvis in 12 patients $(25.5 \%)$, followed by the lower extremities in 11 $(23.4 \%)$, and the thoracopulmonary region in $9(19.2 \%)$. ET of the spine was observed in 4 patients $(8.5 \%)$, of the head and neck in $5(10.6 \%)$, and of the upper extremity and the abdomen in 3 patients each (6.4 and 6.4\%). The median tumor volume was $185 \mathrm{ml}$ (range, 1-2,836 ml). A large tumor volume, with a 100-ml cut-off in EICESS 92 and a 200-ml cut-off in EURO-E.W.I.N.G. 99, was described in 10 patients $(71.4 \%)$ from EICESS 92 and 14 patients (50\%) from EUROE.W.I.N.G. 99. In 5 patients, the tumor volume could not be determined. Thirty-four patients $(72.3 \%)$ had localized disease, and 13 patients $(27.7 \%)$ had metastases at the time of diagnosis.

\section{Treatment}

Sixteen patients were treated according to the EICESS 92 protocol. Five patients $(35.7 \%)$ were stratified into the standard arm. Three patients received the VAIA+VACA combination. One out of 3 completed treatment according to protocol, i.e. 4 cycles of VAIA followed by 10 cycles of VACA. One patient received 4 times VAIA and 5 times VACA, and in 1 patient there was no detailed information about the number of cycles. Two patients had the VAIA+VAIA combination, one of them completing according to protocol with 4 plus 10 cycles of VAIA, and the other one completing 5 times VAIA. Nine patients $(64.3 \%)$ were stratified into the high risk arm. Seven patients received EVAIA. Two out of 7 had 14 cycles according to protocol. Two patients received 10 cycles of EVAIA, 1 patient had 4 cycles, 1 patient 5 cycles of EVAIA followed by 2 times VAIA, and of 1 patient there was no detailed information about the number of cycles. Two patients had VAIA, with 1 patient completing 5 cycles and information unavailable in the other. Two of the 9 patients stratified into the high risk group additionally received a Bu-Mel high dose regimen off protocol. In 2 patients, no detailed information was provided on risk stratification and chemotherapy.

In EURO-E.W.I.N.G. 99, data on induction treatment were available in 30 patients. Twenty-three patients completed 6 cycles of VIDE induction, 3 patients received at least 4 cycles of VIDE induction, and 1 patient each had 3, 5, 7, and 14 cycles; in 1 patient the number of cycles was not documented. For consolidation treatment, 12 of the EURO-E.W.I.N.G. 99 patients over 40 years received VAI, 4 had VAC, and 8 patients were given a high dose regimen with autologous stem cell reinfusion, including 6 who received $\mathrm{Bu}-\mathrm{Mel}$ and 1 with tandem Mel-E. One patient was treated off protocol with high dose etoposide/carboplatin/ifosfamide (ICE) (table 2).

\section{Toxicity}

Toxicity was graded according to modified National Institute of Health Common Toxicity Criteria (NIH CTC). In EICESS 92, grade 3 or 4 neutropenia was seen in 23 of 126 reported EVAIA cycles, and 4 of 98 reported VAIA cycles, thrombocytopenia in 18/126 EVAIA cycles, mucositis and nausea/vomiting in 5/98 VAIA cycles (table 3). Regarding VIDE induction, grade 3 or 4 neutropenia was observed in 89 of 178 reported cycles, thrombocytopenia in 54/178, and anemia in 
Table 2. Chemotherapy

\begin{tabular}{|c|c|c|}
\hline Study & Chemotherapy & Patients, $\mathrm{n}$ \\
\hline \multirow{5}{*}{$\begin{array}{l}\text { EICESS } 92 \\
\text { Standard risk } \\
\text { High risk } \\
\text { High risk, off protocol }\end{array}$} & $4 \mathrm{VAIA}+10 \mathrm{VAIA}$ or $10 \mathrm{VACA}$ & 16 \\
\hline & EVAIA & 5 \\
\hline & VAIA & 9 \\
\hline & $\mathrm{HD} \mathrm{Bu}-\mathrm{Mel}^{\mathrm{a}}$ & 7 \\
\hline & no information & 2 \\
\hline \multirow[t]{17}{*}{ EURO-E.W.I.N.G. 99} & induction & 2 \\
\hline & VIDE & 31 \\
\hline & 6 cycles & 30 \\
\hline & not according to protocol & 25 \\
\hline & 14 cycles & 1 \\
\hline & 7 cycles & 1 \\
\hline & 5 cycles & 1 \\
\hline & 4 cycles & 3 \\
\hline & 3 cycles & 1 \\
\hline & no information & 1 \\
\hline & consolidation: & 24 \\
\hline & VAI & 12 \\
\hline & VAC & 4 \\
\hline & HD Bu-Mel & 6 \\
\hline & HD Double ME & 1 \\
\hline & $\mathrm{ICE}^{\mathrm{a}}$ & 1 \\
\hline & none & 5 \\
\hline
\end{tabular}

${ }^{\mathrm{a}} \mathrm{Bu}-\mathrm{Mel}$ and ICE non-protocol treatment.

VAIA = vincristine, adriamycin, ifosfamide, actinomycin D; VACA = vincristine, adriamycin, cyclophosphamide, actinomycin D; E = etoposide; $\mathrm{VIDE}=$ vincristine, ifosfamide, doxorubicin, etoposide; $\mathrm{VAI}=$ vincristine actinomycin D, ifosfamide; VAC = vincristine, actinomycin D, cyclophosphamide; HD = high dose chemotherapy with autologous stem cell reinfusion, $\mathrm{Bu}-\mathrm{Mel}=$ busulfan-melphalan, Double $\mathrm{ME}=$ tandem high dose melphalan-etoposide; ICE = etoposide, carboplatin, ifosfamide.

22/178. As to consolidation chemotherapy, grade 3 or 4 neutropenia was seen in 28 of $96 \mathrm{VAI}$, and 12 of $32 \mathrm{VAC}$ cycles reported. Grade 3 or 4 thrombocytopenia was reported in 6 of $86 \mathrm{VAI}$, and 4 of 32 VAC cycles.

Less frequently observed grade 3 or 4 toxicity under EURO E.W.I.N.G. 99 treatment included fever, nausea/vomiting, rise of transaminases, stomatitis, esophagitis, and neurotoxicity. High dose therapy was generally associated with grade 4 hematotoxicity as expected; 1 patient showed grade 4 venoocclusive disease after Bu-Mel, 1 showed grade 4 mucosits, and in 3 patients no documentation was available (table 4). No toxicity-related death was observed.

\section{Treatment Delay}

In EICESS 92, treatment delays were reported for 24 cycles, i.e. 5 times due to previous infection, once due to hematotoxicity, 3 times for intercurrent local treatment, once for bladder dysfunction, and once for port-a-cath replacement; in 13 instances the reason was unknown.

Treatment delay in EURO-E.W.I.N.G. 99, defined as more than 5 days postponement of a cycle, was reported for 10
Table 5. Local treatment modalities

\begin{tabular}{lc}
\hline Local therapy & Patients, $\mathrm{n}(\%)$ \\
\hline Total number of patients & $42(100)$ \\
Surgery & $10(23.8)$ \\
Surgery alone & $18(69.2)$ \\
Type of surgery & $4(15.4)$ \\
$\quad$ Radical and wide & $4(15.4)$ \\
$\quad$ Marginal compartmental & \\
$\quad$ Intralesional & \\
Radiotherapy & $7(16.7)$ \\
Surgery plus radiotherapy & $22(52.4)$ \\
Local treatment & $3(7.1)$ \\
\hline
\end{tabular}

Table 6. Histopathological response to chemotherapy according to the criteria of Salzer-Kuntschik [29]

\begin{tabular}{lc}
\hline Histopathological response to chemotherapy & Patients, $\mathrm{n}(\%)$ \\
\hline Good (<10\% viable tumor cells) & $11(73)$ \\
Poor ( $\geq 10 \%$ viable tumor cells) & $4(27)$ \\
Response assessment available & $15(32)$ \\
Response assessment not done & $32(68)$
\end{tabular}

VIDE cycles, i.e. 3 times due to delayed hematological recovery, once due to intercurrent local treatment, and 6 times for other reasons, mainly patient's choice.

The VIDE cycle series was incomplete in 5 patients. The reasons given were patient's choice in 1 patient, death for unknown reason in 1 patient, local treatment after 4 cycles in 1 patient, and unknown reasons in 2 patients. No treatment delays were reported for VAI or VAC consolidation.

\section{Local Treatment}

Data on local treatment were available in 42 patients (table 5). Ten patients $(23.8 \%)$ received surgery alone, 7 patients $(16.7 \%)$ definitive radiotherapy, and 22 patients $(52.4 \%)$ combined modality treatment. Three patients had no local therapy of the primary tumor $(7.1 \%)$. Wide margins were achieved in 18 patients $(69.2 \%)$, resection was marginal in 4 patients $(15.4 \%)$, and tumor removal was incomplete in 4 patients (15.4\%). In 6 patients, no information on surgical margins was available. All patients with marginal or intralesional resection received additional radiotherapy. Three-year EFS in this group was 0.38 (95\% confidence interval (CI) 0.09-0.67) compared to $0.53(95 \%$ CI $0.35-0.68)$ in patients with wide surgical margins $(\mathrm{p}=0.2963)$.

\section{Clinical and Pathological Response}

Clinical response of the primary tumor was assessed after 2 cycles of induction chemotherapy in patients with no primary surgery. Twenty patients were evaluated for response to chemotherapy. Complete or partial response with $>50 \%$ reduction in tumor volume was noted in 11 patients $(55 \%)$. 
Fig. 3. Three-year event-free survival (EFS) and overall survival (OS) in patients with Ewing's tumor diagnosed over the age of 40 years $(n=44)$.

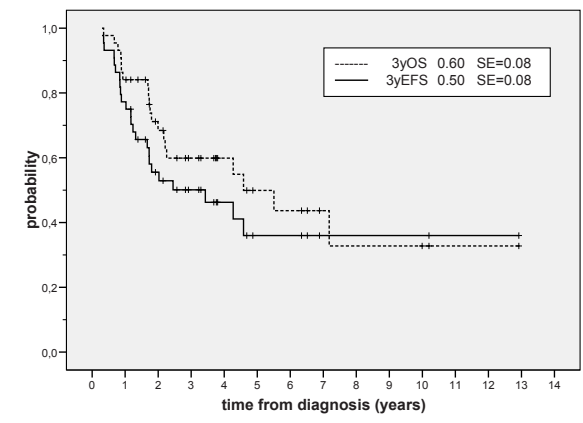

Histopathological response was determined in 15 patients according to the method of Salzer-Kuntschik et al. [29]. Eleven patients $(73 \%)$ achieved good histopathological response $(<10 \%$ viable tumor cells), 4 patients $(27 \%)$ were graded as poor responders with more than $10 \%$ viable tumor cells (table 6).

\section{Survival}

Figure 3 shows EFS and OS. The median time from diagnosis to last follow-up or death was 2.23 years (range, $0.35-12.92$ years). EFS after 3 years was 0.50 (95\% CI 0.34-0.64), and OS was 0.60 (95\% CI 0.43-0.73). 3-year-EFS was 0.56 (0.67) in patients with localized disease, and $0.35(0.43)$ in those with primary dissemination. In order to better classify these results in patients over the age of 40, we compared them with data obtained from 1,591 patients under 40 from EICESS 92 and EURO-E.W.I.N.G. 99. By comparison, 1,591 patients under 40 from EICESS 92 and EURO-E.W.I.N.G. 99 showed a 3-year EFS of 0.57 (95\% CI 0.54-0.59) and 3-year OS of 0.68 (95\% CI $0.66-0.70)$. Thus, patients over 40 had a slightly but not significantly lower survival probability $(p=0.1520 ; p=0.1314)$. If adjusted for metastases at diagnosis and study affiliation, the event risk was 1.33 (95\% CI 0.89-2) for older compared to younger patients $(\mathrm{p}=0.1685)$.

\section{Discussion}

Clinical presentation, treatment modalities, and outcome were analyzed in 47 patients over age 40 diagnosed of ET. ET above age 40 are extremely rare, which is why the majority of analyses concerning treatment, prognostic factors, and outcome focus on pediatric patients, adolescents, and young adults [15-17; 30, 31]. There are only few data and reports available on ET in the older age group, and these refer to ages 16-36 [32, 33], 17-50 [34-36], and 16-55 years [37]. Four of these publications (Picci et al. [33], Siegel et al. [34], Sinkovics et al. [32], Klassen et al. [36]) reported an unfavorable prognosis for adults with non-metastatic ET compared with patients diagnosed in childhood. By contrast, Verill et al. [35] and Fizazi et al. [37] showed outcomes similar to those seen in children in
42 patients between 14 and 52 years and 182 patients between 16 and 55 years, respectively.

It is noteworthy that all of the quoted studies in 'adults' included a large number of patients from the typical age group of ET patients (average median age 20 years: Sinkovics et al. [32], median age 21 years (range, 16-36 years); Verill et al. [35], median age 24 years (range 14-51 years), $31 / 59$ patients $(52.52 \%)$ between 15 and 24 years; Fizazi et al. [37], median age 21.5 years (range, 16-55 years)) rather than focusing on patients beyond the typical age. As yet, only 1 single institution report has been published on patients over 40 years. However, this study was a retrospective analysis covering a wide time span of 28 years and 6 different treatment protocols, and evaluated only patients with localized disease [38].

The analysis reported here includes patients with localized and disseminated disease. Besides, patients were recruited within a relatively short period of time (1992-2005), which implies fairly homogeneous diagnostic procedures and treatment. All patients were treated according to the international clinical trials EICESS 92 or EURO-E.W.I.N.G. 99 which were both open for older patients.

In large controlled ET trials, parameters such as primary disseminated disease, poor histological response to induction treatment, large tumor volume and central axial site, and age $>14$ years have emerged as major unfavorable factors [39-44]. In the present study, 13 out of 47 patients $(27.7 \%)$ over the age of 40 years had presented with distant metastases at the time at diagnosis, which is comparable to data reported elsewhere $[6,15,20,35,42-49]$. There were also no differences regarding tumor site $[2,6,50,51]$ and histopathological response to induction chemotherapy $[33,35,52,53]$. However, the group of patients over the age of 40 did show a rather high number of large tumors $(71.2 \%$ of patients from EURO-E.W.I.N.G. 99 and $50 \%$ of patients from EICESS 92). Interestingly, this cohort also included a high proportion of patients with extra-osseous tumors (15 patients, $31.9 \%$ ). Further investigations are needed to find out whether or not tumor biology is also different in the older age group. It would thus be of major interest to diagnose and treat such patients in controlled studies. Patients younger than 40 years showed a 3-year EFS of 0.57 (95\% CI 0.53-0.59) and 3-year OS of 0.68 (95\% CI 0.66-0.70). Thus, patients over 40 had a slightly but not significantly lower survival probability ( $\mathrm{p}=0.1520 ; \mathrm{p}=0.1314)$.

Chemotherapy-related toxicity is substantial, but predictable and manageable. Most importantly, there were only very few toxicity-related treatment delays, which is in agreement with previously published data [54]. In conclusion, treatment of ET patients over the age of 40 years - similar to that given in the younger age group - should provide for a multimodal treatment concept including combination chemotherapy, complete surgical resection wherever possible, and more radiotherapy. The outcome of our study population is quite comparable to the outcome of pediatric patients and adolescents although the feasibility of applying intense chemotherapy regimes may 
have been restricted in a fair number of patients. Age under these circumstances is not a major poor prognostic feature [35, 37] - the unfavorable prognostic factors in the older age group seem similar to those seen in younger patients [39-44]. Treatment according to the studies designed for younger patients is feasible and effective. It is therefore recommended to enroll older patients into the ongoing Ewing trials. The trial office offers the support of a multidisciplinary team in guiding a patient through the entire treatment for optimal results. This will also help to augment the knowledge on this age group and eventually develop age-adapted treatment concepts.

\section{Acknowledgment}

The authors gratefully acknowledge the excellent secretarial assistance of Regina Kloss.

\section{Supplemental Table Files}

Table 3. EICESS 92 - toxicity according to modified NIH CTC criteria. Table 4. EURO-E.W.I.N.G. 99 - toxicity according to modified NIH CTC criteria.

For further information please refer to www.karger.com/doi/10.1159/000165361.

\section{References}

1 Ewing J: Diffuse endothelioma of bone. Proc N Y Pathol Soc 1921;21:17-24.

$\checkmark 2$ Nesbit ME Jr, Gehan EA, Burgert EO Jr, Vietti TJ, Cangir A, Tefft M, Evans R, Thomas P, Askin FB, Kissane JM, Pritchard DJ, Herrmann J, Neff J, Makley JT, Gilula L: Multimodal therapy for the management of primary, nonmetastatic Ewing's sarcoma of bone: a long-term follow-up of the first intergroup study. J Clin Oncol 1990;8:1664-1674.

-3 Angervall L, Enzinger FM: Extraskeletal neoplasm resembling Ewing's sarcoma. Cancer 1975;36: 240-251.

4 Delattre O, Zucman J, Melot T, Garau XS, Zucker JM, Lenoir GM, Ambros PF, Sheer D, Turc-Carel C, Triche TJ, Aurias A, Thomas G: The Ewing family of tumors - a subgroup of small-round-cel tumors defined by specific chimeric transcripts. N Engl J Med 1994; 331:294-299.

5 Rosen G, Caparros B, Mosende C, McCormick B, Huvos AG, Marcove RC: Curability of Ewing's sarcoma and considerations for future therapeutic trials. Cancer 1978;41:888-899.

6 Kinsella TJ, Miser JS, Waller B, Venzon D, Glatstein E, Weaver-McClure L, Horowitz ME: Long-term follow-up of Ewing's sarcoma of bone treated with combined modality therapy. Int J Radiat Oncol Biol Phys 1991;20:389-395.

7 Craft AW, Cotterill SJ, Bullimore JA, Pearson D Long-term results from the first UKCCSG Ewing's Tumour Study (ET-1). United Kingdom Children's Cancer Study Group (UKCCSG) and the Medical Research Council Bone Sarcoma Working Party. Eur J Cancer 1997;33:1061-1069.

8 Jürgens H, Exner U, Gadner H, Harms D, Michaelis J, Sauer R, Treuner J, Voûte T, Winkelmann W, Winkler K, Göbel U: Multidisciplinary treatment of primary Ewing's sarcoma of bone. A 6-year experience of a European Cooperative Trial. Cancer 1988;61:23-32.

-9 Gasparini M, Lombardi F, Gianni C, Fossati-Bellani F: Localized Ewing's sarcoma: results of integrated therapy and analysis of failures. Eur J Cancer Clin Oncol 1981;17:1205-1209.

10 Zucker JM, Henry-Amar M, Sarrazin D, Blache R, Patte C, Schweisguth O: Intensive systemic chemotherapy in localized Ewing's sarcoma in childhood: a historical trial. Cancer 1983;52:415-423.

11 Deméocq F, Carton P, Patte C, Oberlin O, Sarrazin D, Lemerle J: Traitement du sarcome d'Ewing par chimiotherapie initiale intensive. Presse Med 1984; 13:717-721.
Grier HE: The Ewing family of tumors: Ewing's sarcoma and primitive neuroectodermal tumors. Pediatr Clin North Am 1997;44:991-1004.

13 Burgert EO Jr, Nesbit ME, Garnsey LA, Gehan EA, Herrmann J, Vietti TJ, Cangir A, Tefft M, Evans R, Thomas P, Askin FB, Kissane JM, Pritchard DJ, Neff J, Makley JT, Gilula L: Multimodal therapy for the management of nonpelvic, localized Ewing's sarcoma of bone: intergroup study IESS II. J Clin Oncol 1990;8:1514-1524.

14 Evans RG, Nesbit ME, Gehan EA, Garnsey LA, Burgert EO Jr, Vietti TJ, Cangir A, Tefft M, Thomas P, Askin FB, Kissane JM, Pritchard DJ, Neff J, Makley JT, Gilula L: Multimodal therapy for the management of localized Ewing's sarcoma of pelvic and sacral bones: a report from the second intergroup study. J Clin Oncol 1991;9:1173-1180.

15 Paulussen M, Ahrens S, Dunst J, Winkelmann W, Exner GU, Kotz R, Amann G, Dockhorn-Dworniczak B, Harms D, Müller-Weihrich S, Welte K, Kornhuber B, Janka-Schaub G, Göbel U, Treuner J, Voûte PA, Zoubek A, Gadner H, Jürgens H: Localized Ewing tumor of bone: final results of the Cooperative Ewing's Sarcoma Study CESS 86. J Clin Oncol 2001;19:1818-1829.

16 Strauss SJ, McTiernan A, Driver D, Hall-Craggs M, Sandison A, Cassoni AM, Kilby A, Michelagnoli M, Pringle J, Cobb J, Briggs T, Cannon S, Witt J, Whelan JS: Single center experience of a new intensive induction therapy for Ewing's family of tumors: feasibility, toxicity, and stem cell mobilization properties. J Clin Oncol 2003;21:2974-2981.

17 Anders Kolb E, Kushner BH, Gorlick R, Laverdiere C, Healey JH, LaQuaglia MP, Huvos AG, Qin J, Vu HT, Wexler L, Wolden S, Meyers PA: Longterm event-free survival after intensive chemotherapy for Ewing's family of tumors in children and young adults. J Clin Oncol 2003;21:3423-3430.

18 Schuck A, Ahrens S, Paulussen M, Kuhlen M, Könemann S, Rübe C, Winkelmann W, Kotz R, Dunst J, Willich N, Jürgens H: Local therapy in localized Ewing tumors: results of 1058 patients treated in the CESS 81, CESS 86, and EICESS 92 trials. Int J Radiation Oncol Biol Phys 2003;55:168-177.

19 Paulussen M, Ahrens S, Braun-Munzinger G, Craft AW, Dockhorn-Dworniczak B, Dörffel W, Dunst J, Fröhlich B, Göbel U, Häussler M, Klingebiel T, Koscielniak, Mittler U, Rübe C, Winkelmann W, Voûte PA, Zoubek A, Jürgens H: EICESS 92 (European Intergroup Cooperative Ewing's Sarcoma Study) preliminary results. Klin Päd 1999;211:276-283.
20 Juergens C, Weston C, Lewis I, Whelan J, Paulussen M, Oberlin O, Michon J, Zoubek A, Juergens H, Craft A: Safety assessment of intensive induction with vincristine, ifosfamide, doxorubicin, and etoposide (VIDE) in the treatment of Ewing tumors in the EURO-E.W.I.N.G. 99 clinical trial. Pediatr Blood Cancer 2006;47:22-29.

21 Jürgens H, Craft AW: Euro-E.W.I.N.G.99, European Ewing Tumour Working Initiative of National Groups. Ewing Tumour Studies 1999, EE99, study manual.

22 Oberlin O, Habrand JL: Ewing's sarcoma: towards a common protocol for adults and children. Cancer Radiother 2000;4(suppl 1):141s-144s.

23 Rodriguez-Galindo C, Spunt SL, Pappo AS: Treatment of Ewing sarcoma family of tumors: current status and outlook for the future. Med Pediatr Oncol 2003;40:276-287.

24 Kaplan EL, Meier P: Nonparametric estimation from incomplete observations. J Am Stat Assoc 1958;53:457-481.

25 Peto R, Pike MC, Armitage P, Breslow NE, Cox DR, Howard SV, Mantel N, McPherson K, Peto J, Smith PG: Design and analysis of randomized clinical trials requiring prolonged observation of each patient: II. Analysis and examples. Br J Cancer 1977;35:1-39

26 Mantel N: Evaluation of survival data and two new rank order statistics arising in its consideration. Cancer Chemother Rep 1966;50:163-170.

27 Peto R, Peto J: Asymptotically efficient rank invariant test procedures (with discussion). J Roy Stat Soc A 1972;135:185-206.

28 Cox DR: Regression models and life tables (with discussion). J Roy Stat Soc B 1972;34:187-220.

29 Salzer-Kuntschik M, Delling D, Beron G, Sigmund R: Morphological grades of regression on osteosarcoma after polychemotherapy: Study COSS 80. J Cancer Res Clin Oncol 1983;106:21-24.

30 Hense HW, Ahrens S, Paulussen M, Lehnert M, Jürgens H: Descriptive epidemiology of Ewing's tumor-analysis of German patients from (EI)Cess 1980-1997. Klin Padiatr 1999;211:271-275.

31 Cotterill SJ, Parker L, Malcolm AJ, Reid M, More L, Craft AW: Incidence and survival for cancer in children and young adults in the North of England, 1968-1995: a report from the Northern Region Young Persons' Malignant Disease Registry. Br J Cancer 2000;83:397-403.

32 Sinkovics JG, Plager C, Ayala AG, Lindberg LD, Samuels ML: Ewing sarcoma: its course and treatment in 50 adult patients. Oncology 1980;37: 114-119. 
33 Picci P, Bohling T, Bacci G, Ferrari S, Sangiorgi L, Mercuri M, Ruggieri P, Manfrini M, Ferraro A, Casadei R, Benassi MS, Mancini AF, Rosito P, Cazzola A, Barbieri E, Tienghi A, Brach del Prever A, Comandone A, Bacchini P, Bertoni F: Chemotherapy-induced tumor necrosis as a prognostic factor in localized Ewing's sarcoma of the extremities. J Clin Oncol 1997;15:1553-1559.

-34 Siegel RD, Ryan LM, Antman KH: Adults with Ewing's sarcoma: an analysis of 16 patients at the Dana-Farber Cancer Institute. Am J Clin Oncol 1988;11:614-617.

-35 Verrill MW, Judson IR, Harmer CL, Fisher C, Thomas JM, Wiltshaw E: Ewing's sarcoma and primitive neuroectodermal tumor in adults: are they different from Ewing's sarcoma and primitive neuroectodermal tumor in children? J Clin Oncol 1997;15:2611-2621.

-36 Klassen R, Sastregarau X, Aurias A, et al.: Sarcoma d'Ewing osseoux de l'adulte. Etude anatomoclinique de 30 observations. Bull Cancer 1992;79: 161-167.

>37 Fizazi K, Dohollou N, Blay JY, Guérin S, Le Cesne A, André F, Pouillart P, Tursz T, Binh Bui N: Ewing's family of tumors in adults: multivariate analysis of survival and long-term results of multimodality therapy in 182 patients. J Clin Oncol 1998;16:3736-3743.

\38 Bacci G, Balladelli A, Forni C, Ferrari S, Longhi A, Bacchini P, Alberghini M, Fabbri N, Benassi MS, Briccoli A, Picci P: Adjuvant and neoadjuvant chemotherapy for Ewing sarcoma family tumors in patients aged between 40 and 60. Cancer 2007;109: 780-786.

39 Ladenstein R, Whelan J, Oberlin O, Weston C, Jürgens $\mathrm{H}$ : Multivariate analysis based risk grouping of Ewing tumours (ET) with extrapulmonary metastatic disease (EPMD): final results from the EURO-E.W.I.N.G. 99 study. ASCO Ann Meet Proc Part I, J Clin Oncol 2007;25(suppl):541 (abstr 9562).
40 Kushner BH, Meyers PA, Gerald WL, Healey JH, La Quaglia MP, Boland P, Wollner N, Casper ES, Aledo A, Heller G: Very-high-dose short-term chemotherapy for poor-risk peripheral primitive neuroectodermal tumors, including Ewing's sarco$\mathrm{ma}$, in children and young adults. J Clin Oncol 1995:13:2796-2804.

41 Paulussen M, Braun-Munzinger G, Burdach S, Deneke S, Dunst J, Fellinger E, Gobel U, Mittler U, Treuner J, Voûte PA, et al.: Results of treatment of primary exclusively pulmonary metastatic Ewing sarcoma. A retrospective analysis of 41 patients. Klin Pad 1993;205:210-216.

42 Paulussen M, Ahrens S, Burdach S, Craft A, Dockhorn-Dworniczak B, Dunst J, Fröhlich B, Winkelmann W, Zoubek A, Jürgens H: Primary metastatic (stage IV) Ewing tumor: survival analysis of 171 patients from the EICESS studies. European Intergroup Cooperative Ewing Sarcoma Studies. Ann Oncol 1998;9:275-281.

43 Cotterill SJ, Ahrens S, Paulussen M, Jürgens HF, Voûte PA, Gadner H, Craft AW: Prognostic factors in Ewing's tumor of bone: analysis of 975 patients from the European Intergroup Cooperative Ewing's Sarcoma Study Group. J Clin Oncol 2000; 18:3108-3114.

44 Bacci G, Ferrari S, Bertone F, Rimondini S, Longhi A, Bacchini P, Forni C, Manfrini M, Donati D, Picci P: Prognostic factors in nonmetastatic Ewing's sarcoma of bone treated with adjuvant chemotherapy: analysis of 359 patients as the Instituto Ortopedico Rizzoli. J Clin Oncol 2000;18:4-11.

45 Miser JS, Kinsella TJ, Triche TJ, Steis R, Tsokos M, Wesley R, Horvath K, Belasco J, Longo DL, Glatstein E, Israel MA: Treatment of peripheral neuroepithelioma in children and young adults. J Clin Oncol 1987;5:1752-1758.

46 Hayes FA, Thompson EI, Parvey L, Rao B, Kun L, Parham D, Hustu HO: Metastatic Ewing's sarcoma: remission induction and survival. J Clin Oncol 1987:5:1199-1204.
7 Jürgens H, Bier V, Harms D, Beck J, Brandeis W, Etspüler G, Gadner H, Schmidt D, Treuner J, Winkler K, Göbel U: Malignant peripheral neuroectodermal tumors. A retrospective analysis of 42 patients. Cancer 1988;61:349-357.

48 Marina NM, Etcubanas E, Parham DM, Bowman LC, Green A: Peripheral primitive neuroectodermal tumor (peripheral neuroepithelioma) in children. A review of the St. Jude experience and controversies in diagnosis and management. Cancer 1989;64:1952-1960.

49 Kushner BH, Hajdu SI, Gulati SC, Erlandson RA Exelby PR, Liebermann PH: Extracranial primitive neuroectodermal tumors, the Memorial Sloan-Kettering Cancer Center experience. Cancer 1991;67: 1825-1829.

50 Sailer SL, Harmon DC, Mankin HJ, Truman JT, Suit HD: Ewing's sarcoma: surgical resection as a prognostic factor. Int J Radiat Oncol Biol Phys 1988;15:43-52.

51 Bacci G, Toni A, Avella M, Manfrini M, Sudanese A, Ciaroni D, Boriani S, Emiliani E, Campanacci M: long-term results in 144 localized Ewing's sarcoma patients treated with combined therapy. Cancer 1989;63:1477-1486.

52 Meyers PA, Wunder J, Healey JM, et al.: Ewing's sarcoma/primitive neuroectodermal tumor of bone: histological response to preoperative chemotherapy predicts event-free survival. Proc Am Soc Clin Oncol 1995; 14:441.

53 Oberlin O, Patte C, Demeocq F, Lacombe MJ, Brunat-Mentigny M, Demaille MC, Tron P, Bui BN Lemerle $\mathrm{J}$ : The response to initial chemotherapy as a prognostic factor in localized Ewing's sarcoma. Eur J Cancer Clin Oncol 1985;21:463-467.

54 Juergens C, Weston C, Lewis I, Whelan J, Paulussen M, Oberlin O, Michon J, Zoubek A, Juergens H, Craft A: Safety assessment of intensive induction with vincristine, ifosfomide, doxorubicin, and etoposide (VIDE) in the treatment of Ewing tumors in the EURO-E.W.I.N.G 99 clinical trial. Pediatr Blood Cancer. 2006;47:22-29. 